\title{
Induction of viral and tumour specific CTL responses using antibody targeted HLA class I peptide complexes
}

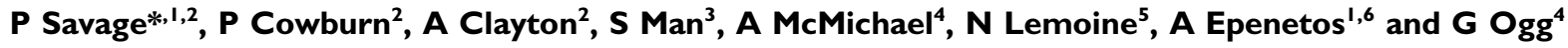 \\ 'Alexis Biotechnology, 81 Harley Street, London WIN IDE, UK; ${ }^{2}$ Cancer Research Wales, Velindre Hospital, Whitchurch, Cardiff CFI4 2TL, UK; ${ }^{3}$ Department of \\ Medicine, University of Wales College of Medicine, Cardiff CFI 4 2TL, UK; ${ }^{4}$ MRC, Human Immunology Unit, IMM, Oxford OX3 9DS, UK; ${ }^{5}$ ICRF Molecular \\ Oncology Unit, Hammersmith Hospital, London WI2 ONN, UK; ${ }^{6}$ Department of Medical Oncology, St Bartholomews Hospital, London ECIA 7BE, UK
}

The production of cytotoxic T cells with specificity for cancer cells is a rapidly evolving branch of cancer therapeutics. A variety of approaches aim to amplify anti-tumour cytotoxic $T$ cell responses using purified peptides, tumour cell lysates or recombinant HLA/peptide complexes in differing antigen presenting systems. Using a two-step biotin-streptavidin antibody targeting system, recombinant HLA-class I/peptide complexes were attached to the surface of B cells via the anti-CD20 B9E9scFvSA antibody-streptavidin fusion protein. Flow cytometry with a conformation dependant monoclonal antibody to HLA class I indicated that targeted HLA-class I/peptide complexes remain on the surface of B cells in culture for periods in excess of $72 \mathrm{~h}$. PBMCs were stimulated in vitro for $8-14$ days using the autologous B cells as antigen presenting cells. Following a single cycle of stimulation specific cytotoxic $T$ cell responses to targeted HLA-A2 complexes containing the MI, BMLFI and Melan A peptides could be demonstrated by tetramer staining and $\mathrm{Cr}$ release assays. With the HLA-A2/BMLFI complex up to $2.99 \%$ of CD8+ve cells were tetramer positive producing $20 \%$ lysis (E:T I0:I) of CIR-A2 target cells in an in vitro cytotoxicity assay compared to baseline levels of $0.09 \%$ tetramer +ve and $2 \%$ lysis in the unstimulated population. PBMCs from a healthy donor treated with two cycles of stimulations with targeted HLA-A2/Melan A complexes, demonstrated expansion of the melanA tetramer +ve population from $0.03 \%$ to $1.4 \%$ producing $15 \%$ lysis of Melan A pulsed target cells. With further consideration to the key variables of HLA/peptide complex density, the ratio of stimulator to effector cells and optimum cytokine support, this system should offer an easy and effective method for the in vitro amplification of specific cytotoxic $T$ cell responses and warrants development for the in vivo induction of cytotoxic $T$ cell responses in cancer therapy. British Journal of Cancer (2002) 86, 1336 - 1342. DOI: I0.1038/sj/bjc/6600223 www.bjcancer.com

(c) 2002 Cancer Research UK

Keywords: cancer; immunotherapy; HLA class I; vaccines; B cells; CD20

A central aim of cancer immunotherapy is the induction of effective cytotoxic T cell (CTL) activity that recognises HLA class I/ peptide complexes that are either specific to or over-represented on tumour cells (Rosenberg, 1996). There is increasing evidence that low levels of CTLs specific for 'tumour' peptides are present in a number of malignancies (Pittet et al, 1999), however the magnitude of these pre-existing responses frequently appears to be insufficient for effective in vivo activity.

The interaction between the HLA class I/peptide complex and the $\mathrm{T}$ cells antigen receptor is the final pathway in the expansion of CD8 +ve CTLs. A range of approaches aim to reach this interaction, starting with either defined tumour associated peptide or more complex cellular based preparations. These methods include vaccination with peptides (Rosenberg et al, 1998), naked DNA (Mincheff et al, 2000) or irradiated tumour cells (Chan and Morton, 1998), these systems rely on processing and presentation by native antigen presenting cells (APCs). Alternatively ex vivo expanded dendritic cells can be used either with peptide pulsing (Hsu et al, 1996; Brossart et al, 2000), loading with tumour lysate (Nestle et al, 1999) or transfected with genes encoding tumour proteins

*Correspondence: Dr P Savage;

E-mail: Philip.savage@velindre-tr.wales.nhs.uk

Received I 8 July 200 I; revised 23 January 2002; accepted 28 January 2002
(Wang et al, 2000a). Recombinant HLA-class I/peptide complexes either immobilised on beads (Lone et al, 1998; Tham et al, 2001), incorporated into antibody based fusion proteins (Cullen et al, 1999), or as recombinant MHC tetramers (Wang et al, 2000b) have also produced effective CTL responses both in vitro and in pre-clinical models. Dendritic cells are the most effective APCs but are present in low numbers in vivo and are difficult to culture, in contrast B cells are present in large numbers, are simple to manipulate in vitro and have been demonstrated to act effectively as APCs inducing specific CTL responses in vivo (Gajewski et al, 2001).

Previously it has been demonstrated that HLA class I/viral peptide complexes targeted to B cells via an antibody delivery system can serve as effective targets for the lytic action of anti-viral CTLs (Ogg et al, 2000; Savage et al, 2002). In this current study we have used a similar system to investigate if the two-step antibody delivery system (see Figure 1) is able to produce the specific expansion of CTLs of chosen specificities from unselected populations of PBMCs.

\section{MATERIALS AND METHODS}

\section{Antibodies}

The B9E9 scFvSA fusion protein contains the single-chain variable region of the murine IgG2a anti-CD20 murine antibody B9E9 fused to the genomic streptavidin of Streptomyces avidinii. The protein is 

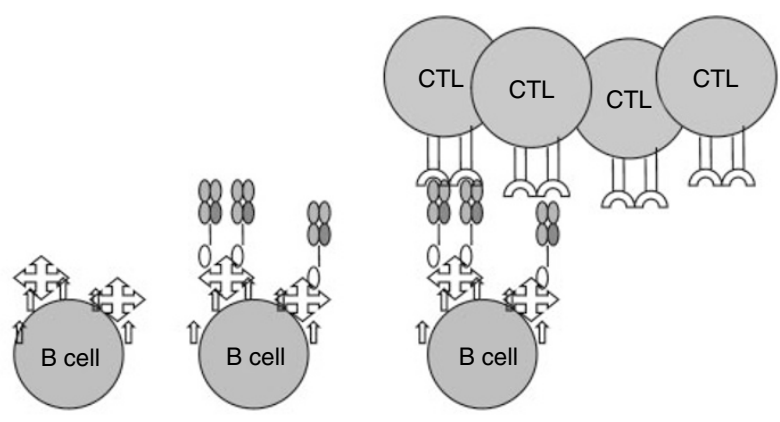

$\Uparrow \quad \mathrm{CD} 20$

究 B9E9 sfvScSA

$\infty$

0 Biotinylated HLA-A2/peptide complex

Figure I Schematic representation of the two-step targeting system delivering HLA-class I peptide complexes to the surface of B cells. Step I is the delivery of the anti-CD20 B9E9 sfvScSA fusion protein. Step 2 the delivery of recombinant biotinylated HLA class I peptide. These steps are followed by the selective proliferation of peptide specific CTLs.

secreted into the periplasm of genetically engineered E. coli as monomeric subunits (43 400 Daltons) that spontaneously fold into soluble tetramers with a molecular weight of 173600 Daltons. The four antigen-binding and biotin-binding sites of the fusion protein retain the functional capabilities of the parent molecules (Schultz et al, 2000). The FITC conjugated monoclonal antibodies used in flow cytometry were anti-MHC class I (W6/32) (Cymbus Biotechnology, Harrow, UK), anti-CD19, anti-CD80 and anti-CD86 (Dako, Ely, UK).

\section{Cells}

The CIR-A2 (Storkus et al, 1989) and Daudi (Klein et al, 1968) cell lines were grown in RPMI $+10 \%$ FCS supplemented with Penicillin and Streptomycin in a $37^{\circ} \mathrm{C}$ incubator with $5 \% \mathrm{CO}_{2}$.

PBMCs were isolated from healthy volunteers and melanoma patients previously documented to be HLA-A2 +ve. Approximately $30 \mathrm{mls}$ of venous blood was obtained by venepuncture and unfractionated PBMCs were obtained by differential centrifugation using Histopaque (Sigma, Poole, UK).

\section{HLA-A2/peptide complex monomers and tetramers}

Recombinant HLA-A2 class I molecules were obtained from ProImmune Ltd (Oxford Science Park, Oxford, UK). In brief, recombinant HLA-A2 heavy chain and beta-2 microglobulin were produced in E. coli. The functional HLA class I/peptide complex were produced by refolding around the peptide of choice and then biotinylation via the Bir A site on the HLA heavy chain (Garboczi et al, 1992; Altman et al, 1996). The peptides used in these experiments were Influenza virus M1 peptide GILGFVFTL (Gotch et al, 1987), Epstein-Barr virus (EBV) BMLF1 peptide GLCTLVAML (Steven et al, 1997) and the modified melanoma associated Melan A peptide ELAGIGILTV (Valmori et al, 1998). The PE conjugated fluorescent HLA-A2/peptide tetramers of the same specificities used for flow cytometric analysis were also obtained from ProImmune.

\section{Targeting of B9E9 scFvSA and HLA-A2/peptide complexes to HLA class I -ve B cells}

HLA class I -ve Daudi cells were used to investigate the binding of the HLA-A2/class I peptide complexes via the B9E9 scFvSA. Cells were washed in PBS and incubated with B9E9 scFvSA diluted in PBS at $10 \mathrm{ug} \mathrm{ml}{ }^{-1}$ for $1 \mathrm{~h}$ at RT. After washing the cells were incubated with either biotinylated HLA-A2/M1 peptide complexes at $0.5 \mu \mathrm{g} \mathrm{ml}^{-1}$ or PBS alone for $30 \mathrm{~min}$ at RT. After further washing the two groups of cells were resuspended in RPMI $+10 \%$ FCS and grown at $37^{\circ} \mathrm{C}$ in a $5 \% \mathrm{CO}_{2}$ atmosphere. At various time points parallel samples of cells were removed, washed and incubated for $30 \mathrm{~min}$ at RT with FITC conjugated W6/32, after washing the cells were analysed by flow cytometry.

\section{The effects of B9E9 scFvSA binding on the expression of co-stimulatory molecules in PBMC B cells}

PBMCs prepared by differential centrifugation were incubated with B9E9 scFvSA $\left(10 \mu \mathrm{g} \mathrm{ml}^{-1}\right)$, IL-7 $\left(10 \mathrm{ng} \mathrm{ml}^{-1}\right)$, B9E9 scFvSA and IL-7 or PBS alone for $1 \mathrm{~h}$ at RT. After washing the cells were placed into tissue culture media and returned to culture at $37^{\circ} \mathrm{C}$. Samples were removed and double stained with $\mathrm{PE}$ conjugated anti-CD19 and either FITC conjugated anti-CD80 or anti-CD86 and analysed on a Becton Dickinson FACScan using FACScomp software.

\section{In vitro immunisation protocol}

PBMCs were incubated with the B9E9 scFvSA $\left(10 \mu \mathrm{g} \mathrm{ml}^{-1}\right)$ diluted in PBS for $1 \mathrm{~h}$ at RT. After washing cells were incubated with the biotinylated HLA class I/peptide complex $\left(0.5 \mu \mathrm{g} \mathrm{ml}^{-1}\right.$ in PBS) for $30 \mathrm{~min}$ at RT. Various controls, omitting the B9E9 scFvSA or the HLA class I/peptide complex were also performed. After washing, cells were placed into 24 -well plates at $3 \times 10^{6}$ cells per well and cultured in RPMI with $10 \%$ human AB serum. IL-7 ( $\mathrm{R}$ and D Systems, Minneapolis, MN, USA) was added on day 1 at $10 \mathrm{ng} \mathrm{ml}^{-1}$ and IL-2 (Chiron, Harefield, UK) was added at $10 \mathrm{U} \mathrm{ml}^{-1}$ on day 4 and every further 3 days following the method described by Lalvani et al (1997). In the experiments with a second stimulation cycle further PBMCs were obtained and treated as above. These new cells were then mixed with the existing culture at a $1: 2$ ratio and the culture continued for a further 8 days.

\section{Flow cytometry and tetramer analysis}

To stain CD8 +ve cells from the PBMC culture approximately $1 \times 10^{6}$ cells were washed in PBS, resuspended and incubated with tetramer solution for $30 \mathrm{~min}$ at $37^{\circ} \mathrm{C}$ followed by FITC conjugated anti-CD8 for $20 \mathrm{~min}$ at $4^{\circ} \mathrm{C}$. After incubation the cells were washed, resuspended in PBS and analysed by dual colour flow cytometry. The results of flow cytometry analysis of dual stained PBMCs are shown with anti-CD8 (Y axis) and HLA-A2/M1 tetramers ( $\mathrm{X}$ axis). Percentage figures relate to the number of tetramer positive CD8 +ve cells from the total CD8 +ve population.

\section{Chromium release assay}

Daudi or CIR-A2 cells were labelled with $2 \mathrm{uCi} / \mathrm{uL}$ of ${ }^{51} \mathrm{Cr}$ (Amersham Pharmacia, UK) for $1 \mathrm{~h}$ at $37^{\circ} \mathrm{C}$ then washed. Daudi cells were sequentially coated with B9E9 scFvSA and HLA-A2/M1 complexes following the method above whilst CIR-A2 cells were pulsed with the peptide of choice at a concentration of $10 \mathrm{uM}$ for $1 \mathrm{~h}$ at $37^{\circ} \mathrm{C}$. The target cells were plated at 3000 cells per well in U bottomed 96 -well plates. PBMCs, media or $5 \%$ Triton X-100 were added to a final volume of $200 \mu \mathrm{l}$. Plates were incubated for $4 \mathrm{~h}$ at $37^{\circ} \mathrm{C}$ in a $5 \% \mathrm{CO}_{2}$ atmosphere and $50 \mu \mathrm{l}$ of supernatant was collected and added to $150 \mu \mathrm{l}$ of scintillant. The specific lysis was calculated as:

$$
\% \text { lysis }=\frac{\text { experimental c.p.m.-spontaneous c.p.m. } \times 100}{\text { maximum c.p.m.-spontaneous c.p.m. }}
$$


The spontaneous release was measured from the cells incubated in media alone, the maximum release was measured from the cells incubated in $5 \%$ Triton.

\section{RESULTS}

Sequential analysis of the binding of biotinylated HLA-A2/ M1 complexes to Daudi B-cell lymphoma cells via B9E9 scFvSA

The time course of the retention of the targeted HLA-A2/M1 complexes retention the HLA class I -ve Daudi cells is demonstrated in the sequential flow cytometry analyses in Figure 2. An increased fluorescence signal is demonstrated in the targeted cells which decreases with time. However a positive signal is still present at $72 \mathrm{~h}$ and it is probable that HLA class I/peptide complexes persist at functional levels beyond this time.

\section{Effects of B9E9 scFvSA binding on the expression of co-stimulatory molecules in PBMC B cells}

Figure 3 demonstrates that the addition of B9E9 scFvSA has no detectable effect on the expression of CD80 or CD86 on the B cells within the PBMC population. The results show the flow cytometry results for CD19 +ve cells at $3 \mathrm{~h}$ and $24 \mathrm{~h}$. PBMCs treated with IL7 alone or the combination of B9E9 scFvSA and IL-7 also demonstrated no change in the levels of expression of CD80 and CD86 (data not shown).

\section{Induction of CTL activity with targeted HLA class I/peptide complexes}

The ability of the antibody targeted complexes to stimulate CTL expansion was initially examined with the HLA-A2/M1 combination. In Figure 4 the tetramer analysis of the CD8+ve/HLA-A2/M1 positive cells within the unstimulated PBMCs (1), PBMCs targeted with the B9E9 scFvSA (2), and PBMCs exposed to free soluble HLA-A2/M1 complexes at $0.1 \mathrm{ng} \mathrm{ml}^{-1}$ (3) demonstrate values of $0.06 \%$ to $0.22 \%$. In contrast the PBMCs targeted with the B9E9 scFvSA and HLA-A2/M1 complexes (4) demonstrated $2.33 \%$ tetramer positive $\mathrm{CD} 8+\mathrm{ve}$ cells. Using the unfractionated PBMCs at E:T $10: 1$, a $4 \mathrm{~h}$ Cr release assay, using HLA-A2/M1 coated Daudi cells as target cells, demonstrated a maximum of $10 \%$ lysis from the three control experiments but $24 \%$ from the PBMCs stimulated with HLA-A2/M1 complexes attached via the B9E9 scFvSA fusion protein.

\section{Induced CTL responses are specific for the targeted complex}

To confirm the specificity of CTL expansion, PBMCs were targeted with either B9E9 scFvSA alone (A) or B9E9 scFvSA and HLA-A2/ BMLF1 complexes (B).

In Figure 5 the tetramer analysis of the PBMCs targeted with B9E9 scFvSA alone demonstrates background staining of $0.04 \%$ with HLA-A2/M1 and $0.09 \%$ with HLA-A2/BMLF1. In the $\mathrm{Cr}$ release assay against CIR-A2 cells either native or pulsed with M1 or BMLF1 peptide the PBMCs showed no significant activity. In contrast PBMCs targeted with the HLA-A2/BMLF1 complexes demonstrate $2.99 \%$ staining with the HLA-A2/BMLF1 tetramer but with only a background staining level of $0.01 \%$ with the HLA-A2/M1 tetramer. These cells produced $20 \%$ lysis of the
CD80
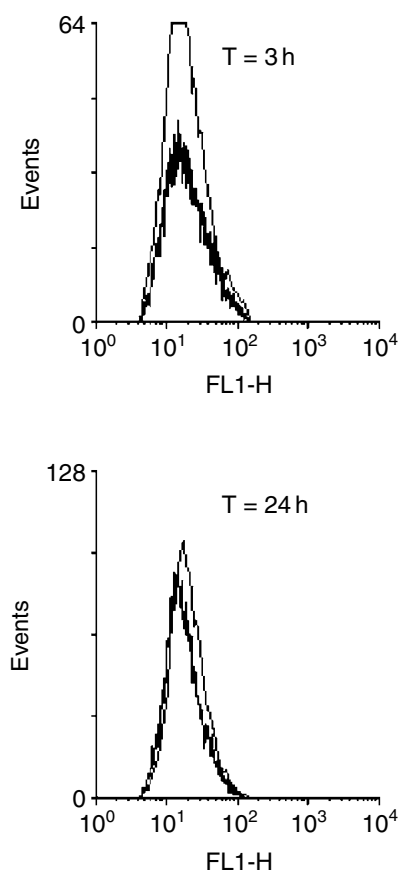

CD86
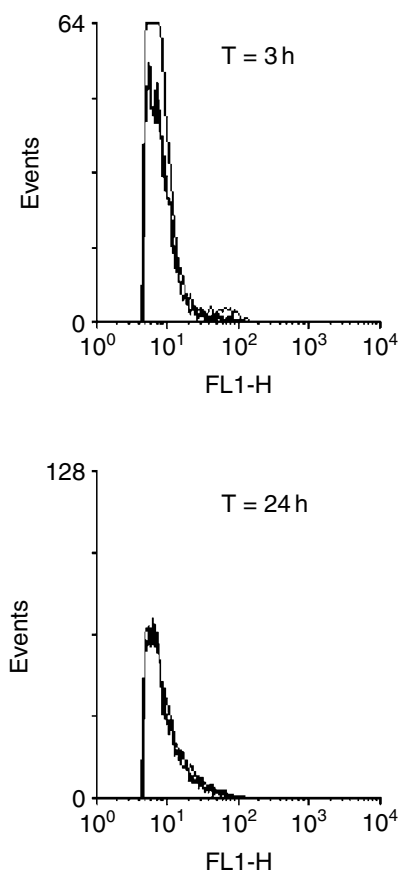

Figure 3 Sequential flow cytometry analysis of expression of CD80 and CD86 on CDI9 + ve B cells within the PBMC population. The unstimulated controls are shown on the narrow trace, the experimental results from PBMCs targeted with the B9E9 sfvScSA are shown in bold.
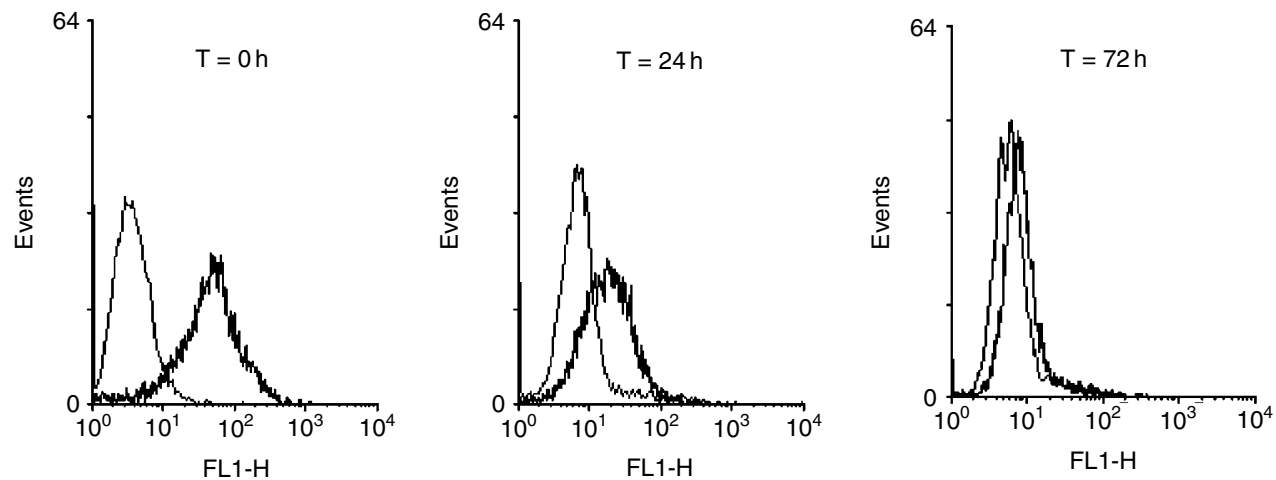

Figure 2 Time course analysis of HLA-A2/MI complexes immobilised on the surface of HLA-class I - ve Daudi cells via B9E9 sfvScSA. Complexes are detected via the binding of W6/32 which binds conformationally correct HLA-class I. Daudi cells targeted with B9E9 sfvScSA alone are shown in grey, in black are Daudi cells targeted with B9E9 sfvScSA and HLA-A2/MI. 


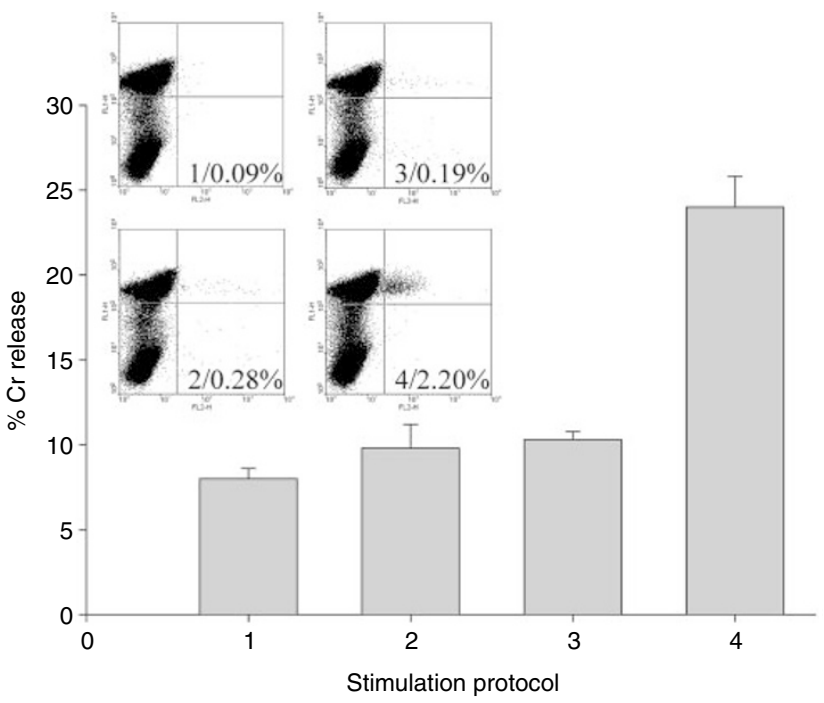

Figure 4 FACs and $\mathrm{Cr}$ release assay results from PBMCs stimulated with targeted HLA-A2/MI complexes. Tetramer results demonstrate staining with anti-CD8 and HLA-A2/MI tetramer. The $\mathrm{Cr}$ release assay demonstrates activity against Daudi cells bearing HLA-A2/MI complexes. Stimulation protocols: I/ PBMCs alone, 2/ PBMCs + B9E9 sfvScSA, 3/ PBMCs + free HLA-A2/BMLFI, 4/ PBMCs + B9E9 sfvScSA + HLA-A2/BMLFI.

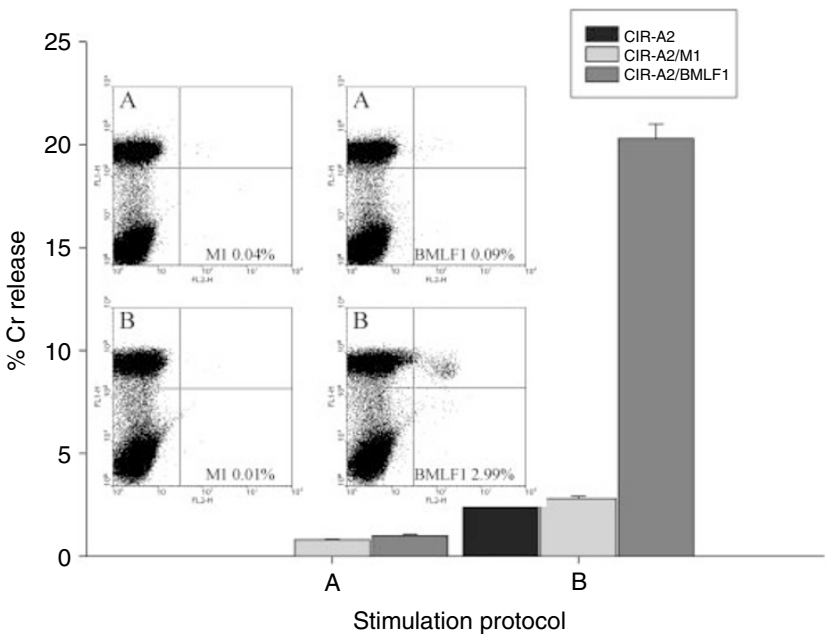

Figure $5 \quad F A C s$ and $\mathrm{Cr}$ release assay results from $\mathrm{PBMCs}$ stimulated with either (A) B9E9 sfvScSA alone or (B) B9E9 sfvSCSA and targeted HLA-A2/ $\mathrm{BMLFI}$ complexes. Tetramer staining results are shown for both HLA-A2/ $\mathrm{MI}$ and HLA-A2/BMLFI. The $\mathrm{Cr}$ release assay demonstrates PBMC at E:T I0: I against native/MI/BMLFI peptide pulsed CIR-A2 target cells.

BMLF1 pulsed CIR-A2 target cells without any significant action on native or M1 pulsed cells.

\section{CTL responses to a single cycle of stimulation with HLA-A2/peptide complexes in healthy donors and melanoma patients}

The numerical values of the tetramer results from PBMCs from a series of healthy donors and melanoma patients are demonstrated in Table 1. In response to stimulation with targeted HLA-A2/M1 complexes a greater than five-fold increase in the number of tetramer +ve cells are seen in six of the eight volunteers and one of two melanoma patients. From the HLA-A2/BMLF1 stimulated cells one of the five volunteers showed a greater than five-fold increase with two others showing apparent increases. In response to targeted HLA-A2/Melan A complexes greater than three-fold increases in tetramer positive cells were seen in three of four volunteers and in one of the melanoma patients.

\section{CTL responses to HLA-A2/M1 and Melan A can be enhanced by a repeated stimulation}

Figure 6 demonstrates the CTL responses produced by two rounds of in vitro stimulation using the same HLA-A2/peptide complex. The $4 \mathrm{~h}$ Cr release assay (E:T 20:1) demonstrates that PBMCs stimulated with targeted HLA-A2/M1 complexes on both day 1 and day 8 produce $14 \%$ lysis of the CIR-A2 M1 pulsed cells compared with $3 \%$ lysis of native and $6 \%$ lysis of CIR-A2 melanA pulsed cells. The increase in HLA-A2/M1 specific CTLs is shown in the tetramer series with $0.09 \%$ from unstimulated cells (1A), $0.68 \%$ after one cycle (1B) and $2.32 \%$ after two cycles (1C). In this donor similar results were seen with responses to melan A with a $15 \%$ lysis of CIR-A2 cells pulsed with the Melan A peptide and increases in tetramer staining from a background of $0.06 \%, 0.16 \%$ after one cycle and $1.40 \%$ after two cycles. In this experiment cells subject to one cycle of stimulation did not produce detectable activity in the Cr release assay (data not shown).

Table I Frequencies of tetramer+ve CTLs to HLA-A2/MI, BMLFI and Melan-A in healthy donors or *melanoma patients before and after I round of in vitro stimulation

\begin{tabular}{lcccccccc}
\hline & \multicolumn{2}{c}{ HLA-A2+MI } & & \multicolumn{2}{c}{ +BMLFI } & & \multicolumn{2}{c}{ +MelanA } \\
\cline { 2 - 3 } Donor & Pre & I Cycle & & Pre & I Cycle & & Pre & I Cycle \\
\hline RT & 0.21 & 1.08 & & 0.54 & 0.63 & & - \\
SL & 0.04 & 0.41 & & 0.28 & 0.26 & & - \\
JaR & 0.00 & 0.32 & & 0.30 & 0.85 & & - & - \\
LOB & 0.00 & 0.01 & & 0.08 & 0.31 & & - & - \\
LL & 0.09 & 2.20 & & 0.09 & 2.99 & & 0.06 & 0.26 \\
CJ & 0.16 & 0.57 & & - & - & & 0.04 & 0.13 \\
JuR & 0.07 & 0.52 & & - & - & & 0.09 & 0.08 \\
DV & 0.07 & 0.80 & & - & - & & 0.03 & 0.14 \\
BB* & 0.00 & 0.22 & & - & - & & 0.41 & 1.33 \\
DB* & 0.36 & 0.91 & & - & - & & 0.42 & 0.21 \\
\hline
\end{tabular}

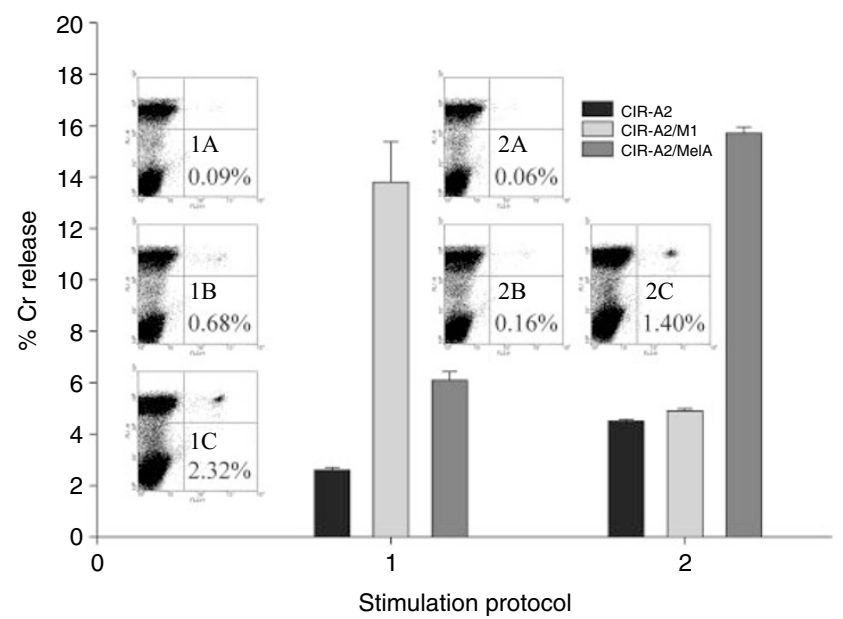

Figure 6 FACs and $\mathrm{Cr}$ release assay results from PBMCs stimulated twice with either (I) targeted HLA-A2/MI complexes or (2) targeted HLA-A2/Melan A complexes. Tetramer results are $(\mathbf{A})$ unstimulated, $(\mathbf{B})$ targeted once and $(\mathbf{C})$ targeted twice. The $\mathrm{Cr}$ release assay with twice targeted PBMCs shows the activity against native and peptide pulsed CIR-A2 cells at $E: T 20:$ I. 


\section{DISCUSSION}

The induction of an effective immune response against malignant cells has been an aim of cancer research for over a century. With the increasing understanding of how the immune system can differentiate between normal and malignant cells a number of cancer vaccine approaches have been examined. To date many of these have centred on the use of undefined antigens via tumour cell lysates or irradiated cells. However with the identification of a number of potential tumour peptide epitopes (Boon and van der Bruggen, 1996; Vonderheide et al, 1999) and the ease of manufacture of recombinant HLA class I peptide complexes (Garboczi et al, 1992) it is now feasible to consider highly specific approaches to cancer vaccine strategies.

Purified immobilised HLA class I/peptide complexes have been shown to interact and stimulate CTLs when attached to tissue culture plates (Kane et al, 1989), chemically attached to cells (Anjuere et al, 1995; Walter et al, 1997) or when coated onto beads (Motta et al, 1998). More recently antibody targeted HLA class I/ peptide complexes have been demonstrated to successfully interact with CTLs to permit lysis of targeted cells in vitro (Ogg et al, 2000; Robert et al, 2000).

The ability of B cells targeted with HLA class I/peptide complexes to induce CTL responses is clearly shown in Figures 4, 5 and 6. In vitro CTL responses demonstrated by tetramer and $\mathrm{Cr}$ release assays were obtained when the HLA class I/peptide complexes were targeted to PBMCs pre-treated with the B9E9 scFvSA fusion protein. In contrast free HLA class I/peptide complexes produced no apparent responses indicating the requirement for either multimerisation or immobilisation of HLA class I/ peptide complexes for effective CTL stimulation as previously described (Abastado et al, 1995; Motta et al, 1998). The specificity of the CTL expansion is confirmed by the results shown in Figure 5 where increases in tetramer staining and lysis of peptide pulsed target cells was only seen in response to stimulation with that specific HLA/peptide complex. The ability of this system to further increase responses by repeated stimulation is shown in the tetramer stain results of Figure 6 . Here the frequencies of CTLs reactive with HLA-A2/M1 increase from $0.09 \%$ to $2.32 \%$ after a second cycle. In this donor the MelanA results of $0.06 \%$ and $1.4 \%$ show as similar pattern, with positive $\mathrm{Cr}$ release assays after two cycles.

The efficiency of CTL induction has previously been shown to be related to the stability and length of expression of the HLA class-I complex on the surface of antigen presenting cells (Van der Burg et al, 1996; Valmori et al, 1998; Micheletti et al, 1999). In this antibody targeting system we have aimed to optimise the time course for expression of the HLA class I complexes, by using complexes with documented long half lives and a high affinity binding system to a non-internalising $\mathrm{B}$ cell marker. The ability of these complexes to persist in a conformationally correct form for at least $72 \mathrm{~h}$ on the surface of the B cells is demonstrated in Figure 2. It is probable that functionally active levels of complexes remain on the surface of the $B$ cells for a longer period as we have previously shown that CTLs can interact efficiently with B cells with levels of targeted HLA below that detectable by flow cytometry (Savage et al, 2002).

The data in Figure 3 demonstrates that binding of the B9E9 scFvSA to the B cells within the PBMCs either alone or in conjunction with IL-7 had no effect on the expression of B80 and B86. Whilst the enhanced expression of co-stimulatory molecules generally increases CTL responses, it has previously been demonstrated that effective CTL can be produced without accessory molecule expression, particularly when high epitope densities are used (Wang et al, 2000b).

At present there has been only limited optimisation of this in vitro stimulation protocol and it is apparent from Table 1 that there is considerable variation in the level of CTL responses produced from different individuals. However the ability to produce CTL responses to viral peptides in the majority of donors from a single round of in vitro immunisation compares favourably with in vitro results from both peptide pulsing (Lalvani et al, 1997) and dendritic cells (Larsson et al, 2000). Further work is in progress to optimise the system, however it was observed in the experimental cultures using targeted HLA class I/peptide complexes there was significant inhibition of proliferation compared to those targeted with the B9E9 fusion protein alone (data not shown). It is possible that the effect of the supraphysiological stimulation prevents expansion of the specific CTL population either via a direct apoptotic action or the result of high levels of cytokine production within the closed system. Studies in mice have shown that increased antigenic density can result in higher CTL activity but produces a significant reduction at very high densities (Wherry et al, 1999). Similarly in human systems the presence of supra-optimal levels of HLA class I complexes can lead to apoptosis rather than expansion of stimulated CD8 +ve CTLs (Alexander-Miller et al, 1998). As CD20 is present at approximately 50000 copies per B cell (Marti et al, 1992), saturated binding of HLA class I/peptide complexes could result in 50000-200000 copies of a single peptide/HLA class I combination per cell. This is significantly higher than produced by peptide pulsing which results in peptide placement in 5000 copies of an individual HLA allele (Delon et al, 1998) out of a total allele number of $10^{5}$ per B cell (Kageyama et al, 1995; McCune et al, 1975). Additionally the stability of the recombinant complexes appears to be greater than those produced by peptide pulsing which have an average half life of only $2.5-4 \mathrm{~h}$ (Wataya et al, 2001) which may further increase the strength and duration of $\mathrm{T}$ cell activation.

The B9E9 scFvSA fusion protein is currently in clinical trials for the treatment of $\mathrm{B}$ cell lymphoma using radiolabelled biotin as the effector function. The ease of administration, lack of toxicity and option for repeated doses suggest that using this molecule in a vaccine strategy should be feasible. To date recombinant HLA class I molecules are yet to be administered to cancer patients, however as endogenous HLA class I molecules circulate in health and in increased levels in a number of illnesses (McMillan et al, 1997) they are unlikely to have any major direct toxicity.

In this preliminary work we have focused on stimulation with a single HLA class I/peptide complex, however the ability to make these recombinant molecules of any chosen HLA class I/peptide combination should allow for vaccination with a range of complexes either sequentially or concurrently. As the stability of the HLA class I/peptide complexes appears to vary considerably with the identity of the peptide (Valmori et al, 1998) and stability is closely linked to the immunogenicity of a chosen HLA class I/ peptide complex, it is possible that recombinant molecules that incorporate the peptide/HLA heavy chain/beta-2-microglobulin into fusion proteins may offer potential benefits.

The initial clinical studies will use PBMCs targeted with complexes ex vivo, which will allow accurate administration of designated numbers of targeted cells at the optimum epitope density. This approach should also minimise the potential immunogenicity of the streptavidin in the fusion protein and the potential risk of uncontrolled CTL expansion that could occur with intravenous HLA classI/complex administration that would result in the targeting of the total $\mathrm{B}$ cell population.

The ability of antibody targeted HLA class I/peptide complexes to specifically induce the expansion of CTLs to a single specificity should prove useful for in vitro studies analysing the endogenous CTL response or the effects of other in vivo procedures. Potentially this system could also be used for the ex vivo production of CTLs for the adoptive immunotherapy of cancer and other diseases. However a vaccination procedure based on targeting HLA class $\mathrm{I} /$ peptide complexes to $\mathrm{B}$ cells in vivo via the antibody delivery system could offer significant advances in both the applicability and effectiveness of cancer vaccines. 


\section{REFERENCES}

Abastado J, Lone Y, Casrouge A, Boulot G, Kourilsky P (1995) Dimerization of soluble major histocompatability complex-peptide complexes is sufficient for activation of $t$ cell hybridoma and induction of unresponsiveness. J Exp Med 182: 439-447

Alexander-Miller MA, Derby MA, Sarin A, Henkart PA, Berzofsky JA (1998) Supraoptimal peptide-major histocompatability complex causes a decrease in Bcl-2 levels and allows tumour necrosis factor alpha receptor IImediated apoptosis of cytotoxic T lymphocytes. J Exp Med 188: $1391-$ 1399

Altman JD, Moss PA, Goulder PJ, Barouch DH, McHeyzer-Williams MG, Bell JI, McMichael AJ, Davis MM (1996) Phenotypic analysis of antigenspecific T lymphocytes. Science 274: 94-96

Anjuere F, Horvath C, Cerottini JC, Luescher IF (1995) Induction of CTL in vivo by major histocompatibility complex class I-peptide complexes covalently associated on the cell surface. Eur J Immunol 25: 1535-1540

Boon T, van der Bruggen P (1996) Human tumor antigens recognized by $T$ lymphocytes. J Exp Med 183: 725 -729

Brossart P, Wirths S, Stuhler G, Reichardt VL, Kanz L, Brugger W (2000) Induction of cytotoxic T-lymphocyte responses in vivo after vaccinations with peptide-pulsed dendritic cells. Blood 96: $3102-3108$

Chan AD, Morton DL (1998) Active immunotherapy with allogeneic tumor cell vaccines: present status. Semin Oncol 25: 611-622

Cullen CM, Jameson SC, DeLay M, Cottrell C, Becken ET, Choi E, Hirsch R (1999) A divalent major histocompatibility complex/IgG1 fusion protein induces antigen-specific $\mathrm{T}$ cell activation in vitro and in vivo. Cell Immunol 192: $54-62$

Delon J, Bercovici N, Raposo G, Liblau R, Trautmann A (1998) Antigendependent and -independent $\mathrm{Ca} 2+$ responses triggered in $\mathrm{T}$ cells by dendritic cells compared with B cells. J Exp Med 188: 1473-1484

Gajewski TF, Fallarino F, Ashikari A, Sherman M (2001) Immunization of HLA-A2 ${ }^{+}$melanoma patients with MAGE-3 or MelanA peptide-pulsed autologous peripheral blood mononuclear cells plus recombinant human interleukin 12. Clin Can Res 7: 895s-901s

Garboczi DN, Hung DT, Wiley DC (1992) HLA-A2-peptide complexes: refolding and crystallization of molecules expressed in Escherichia coli and complexed with single antigenic peptides. Proc Natl Acad Sci USA 89: $3429-3433$

Gotch F, Rothbard J, Howland K, Townsend A, McMichael A (1987) Cytotoxic $\mathrm{T}$ lymphocytes recognize a fragment of influenza virus matrix protein in association with HLA-A2. Nature 326: 881-882

Hsu FJ, Benike C, Fagnoni F, Liles TM, Czerwinski D, Taidi B, Engleman EG, Levy R (1996) Vaccination of patients with B-cell lymphoma using autologous antigen-pulsed dendritic cells. Nat Med 2: 52-58

Kageyama S, Tsomides TJ, Sykulev Y, Eisen HN (1995) Variations in the number of peptide-MHC class I complexes required to activate cytotoxic $\mathrm{T}$ cell responses. J Immunol 154: 567-576

Kane KP, Vitiello A, Sherman LA, Mescher MF (1989) Cytolytic T-lymphocyte response to isolated class I H-2 proteins and influenza peptides. Nature 340: 157-159

Klein E, Klein G, Nadkarni JS, Nadkarni JJ, Wigzell H, Clifford P (1968) Surface IgM-kappa specificity on a Burkitt lymphoma cell in vivo and in derived culture lines. Cancer Res 28: 1300-1310

Lalvani A, Dong L, Ogg G, Pathan AA, Newell H, Hill AVS, McMichael AJ, Rowland-Jones S (1997) Optimisation of a peptide-based protocol employing IL-7 for in vitro restimulation of human cytotoxic T lymphocyte precursors. J Imm Methods 210: 65-77

Larsson M, Messmer D, Somersan S, Fonteneau JF, Donahoe SM, Lee M, Dunbar PR, Cerundolo V, Julkunen I, Nixon DF, Bhardwaj N (2000) Requirement of mature dendritic cells for efficient activation of influenza A-specific memory CD8+ T cells. J Immunol 165: 1182-1190

Lone YC, Motta I, Mottez E, Guilloux Y, Lim, A, Demay F, Levraud JP, Kourilsky P, Abastado JP (1998) In vitro induction of specific cytotoxic T lymphocytes using recombinant single-chain MHC classI/peptide complexes. J Immunother 21: 283-294

Marti GE, Faguet G, Bertin P, Agee J, Washington G, Ruiz S, Carter P, Zenger V, Vogt R, Noguchi P (1992) CD20 and Cd5 expression in B-chronic lymphocytic leukaemia. Ann NY Acad Sci 651: 480-483

McMillan RW, Gelder FB, Zibari GB, Aultman DF, Adamashvili I, McDonald JC (1997) Soluble fraction of class I human histocompatibility leukocyte antigens in the serum of liver transplant recipients. Clin Transplant 11: $98-103$
Micheletti F, Bazzaro M, Canella A, Marastoni M, Traniello S, Gavioli R (1999) The lifespan of major histocompatability complex calssI/peptide complexes determines the efficiency of cytotoxic $\mathrm{T}$ lymphocyte responses. Immunology 96: 411-415

Mincheff M, Tchakarov S, Zoubak S, Loukinov D, Botev C, Altankova I, Georgiev G, Petrov S, Meryman HT (2000) Naked DNA and adenoviral immunizations for immunotherapy of prostate cancer: a phase I/II clinical trial. Eur Urol 38: 208-217

McCune JM, Humphreys RE, Yocum RR, Strominger JL (1975) Enhanced representation of HLA antigens on human lymphocytes after mitogenesis induced by phytohemagglutinin or Epstein Barr virus. Proc Natl Acad Sci USA 72: 3206-3209

Motta I, Lone YC, Kourilsky P (1998) In vitro induction of naïve cytotoxic T lymphocyte with complexes of peptide and recombinant MHC class I molecules coated onto beads: role of TCR/ligand density. Eur J Immunol 28: $3685-3695$

Nestle FO, Alijagic S, Gilliet M, Sun Y, Grabbe S, Dummer R, Burg G, Schadendorf D (1998) Vaccination of melanoma patients with peptide- or tumor lysate-pulsed dendritic cells. Nat Med 4: 328-332

Ogg GS, Dunbar PR, Cerundolo V, McMichael AJ, Lemoine NR, Savage P (2000) Sensitization of tumour cells to lysis by virus-specific CTL using antibody-targeted MHC class I/peptide complexes. $\mathrm{Br} J$ Cancer 82: $1058-1062$

Pittet M, Valmori D, Dunbar PR, Speiser DE, Lienard D, Lejeune F, Fleischhauer K, Cerundolo V, Cerottini J-C, Romero P (1999) High frequencies of naïve Melan-A/Mart-1 specific CD8+ T cells in a large proportion of human histocompatability leukocyte antigen (HLA)-A2 individuals. $J$ Exp Med 190: 705-716

Robert B, Guillaume P, Luescher I, Romero P, Mach J-P (2000) Antibodyconjugated MHC class I tetramers can target tumor cells for specific lysis by T lymphocytes. Eur. J Immunol 30: 3165-3170

Rosenberg SA (1996) Development of cancer immunotherapies based on identification of the genes encoding cancer regression antigens. $J$ Natl Cancer Inst 88: $1635-1644$

Rosenberg SA, Yang JC, Schwartzentruber DJ, Hwu P, Marincola FM, Topalian SL, Restifo NP, Dudley ME, Schwarz SL, Spiess PJ, Wunderlich JR, Parkhurst MR, Kawakami Y, Seipp CA, Einhorn JH, White DE (1998) Immunologic and therapeutic evaluation of a synthetic peptide vaccine for the treatment of patients with metastatic melanoma. Nat Med 4: $321-327$

Savage P, Cowburn P, Clayton A, Man S, Lawson T, Ogg G, Lemoine N, McMichael A, Epenetos A (2002) Anti-viral Cytotoxic T cells inhibit the growth of cancer cells with antibody targeted MHC class I/peptide complexes in SCID mice. Int J Cancer 98: $561-566$

Schultz J, Lin Y, Sanderson J, Zuo Y, Stone D, Mallett R, Wilbert S, Axworthy D (2000) A tetravalent single-chain antibody-streptavidin fusion protein for pretargeted lymphoma therapy. Cancer Res 60: 6663-6669

Steven NM, Annels NE, Kumar A, Leese AM, Kurilla MG, Rickinson AB (1997) Immediate early and early lytic cycle proteins are frequent targets of the Epstein-Barr virus induced cytotoxic T cell responses. J Exp Med 185: $1605-1617$

Storkus WJ, Alexander J, Payne JA, Cresswell P, Dawson JR (1989) The alpha 1/alpha 2 domains of class I HLA molecules confer resistance to natural killing. J Immunol 143: 3853-3857

Tham EL, Jensen PL, Mescher MF (2001) Activation of antigen-specific T cells by artificial cell constructs having immobilized multimeric peptideclass I complexes and recombinant B7-Fc proteins. J Immunol Methods 249: $111-119$

Valmori D, Fonteneau J-F, Lizana CM, Gervois N, Lienard D, Rimoldi D, Jongeneel V, Jotereau F, Cerottini J-C, Romero P (1998) Enhanced generation of specific tumour reactive CTL in vitro by selected Melan-A/MART-1 immunodominant peptide analogues. J Immunol 160: 1750 - 1758

Van der Burg SH, Visseren MJW, Brandt RMP, Kast WM, Melief CJM (1996) Immunogenecity of peptides bound to MHC class I molecules depends on the MHC-peptide complex stability. J Immunol 156: 3308-3314

Vonderheide RH, Hahn WC, Schultze JL, Nadler LM (1999) The telomerase catalytic subunit is a widely expressed tumor-associated antigen recognised by cytotoxic T lymphocytes. Immunity 10: 673-679 
Walter JB, Brander C, Mammen M, Garboczi DN, Kalams SA, Whitesides G, Walker BD, Eisen HN (1997) Stimulation of human cytotoxic T cells with HIV-1-derived peptides presented by recombinant HLA-A2 peptide complexes. Int Immunol 9: 451-459

Wang TL, Ling M, Shih IM, Pham T, Pai SI, Lu Z, Kurman RJ, Pardoll DM, Wu TC (2000a) Intramuscular administration of E7-transfected dendritic cells generates the most potent E7-specific anti-tumor immunity. Gene Therapy 7: 726-733

Wang B, Maile R, Greenwood R, Collins EJ, Frelinger JA (2000b) Naive $\mathrm{CD} 8+\mathrm{ve} \mathrm{T}$ cells do not require costimulation for proliferation and differentiation into cytotoxic effector cells. J Immunol 164: 1216-1222

Wataya H, Kamikawaji N, Nakanishi Y, Takayama K, Hara N, Sasazuki T (2001) Quatitation of HLA-A ${ }^{\star} 0201$ bound tumor associated antigens on a peptide pulsed B cell line. Hum Immunol 62: 125-132

Wherry EJ, Puorro KA, Porgador A, Eisenlohr LC (1999) The induction of virus specific CTL as a function of increasing epitope expression: responses rise steadily until excessively high levels of epitope are attained. J Immunol 163: $3735-3745$ 